\title{
Classification of Lactobacillus reuteri by Restriction Endonuclease Analysis of Chromosomal DNA
}

\author{
MARIE STÅHL AND GÖRAN MOLIN* \\ Laboratory of Food Hygiene, Department of Food Technology, \\ Chemical Center, S-221 00 Lund, Sweden
}

\begin{abstract}
A total of 14 field strains originally labeled Lactobacillus reuteri, 4 field strains of Lactobacillus fermentum, and 12 Lactobacillus type strains, as well as four additional reference strains, were classified by performing a restriction endonuclease analysis of chromosomal DNAs digested with $A s p$ 718, ClaI, and EcoRI. The patterns were analyzed by using (i) Jaccard coefficients and the unweighted pair group algorithm with arithmetic averages and (ii) principal-component analysis (PCA) and soft independent modeling of class analogy (SIMCA). Grouping by using the Jaccard coefficients and the unweighted pair group algorithm with arithmetic averages resulted in six clusters, defined at a similarity level of $69 \%$. Cluster 1 comprised 10 field strains of $L$. reuteri, Lactobacillus sp. strain DSM 20056, and L. reuteri DSM $20016^{T}$ (T = type strain) and could be divided into four subclusters. Cluster 2 included two $L$. reuteri field strains. Cluster 3 included one field strain labeled $L$. reuteri and one field strain labeled $L$. fermentum. Cluster 4 could be divided into three subclusters and included two field strains labeled $L$. fermentum, one reference strain and the type strain of $L$. fermentum, and four additional type strains. Cluster 5 contained two Lactobacillus plantarum strains. Cluster 6 included two type strains. The two numerical methods gave the same general results, but the PCA-SIMCA method resulted in a more complete view of the relationships. The SIMCA analysis grouped $L$. reuteri DSM $20016^{\mathrm{T}}$, Lactobacillus $\mathrm{sp}$. strain DSM 20056, and, with one exception, all of the $L$. reuteri field strains as a "class." Lactobacillus helveticus DSM $20075^{T}$ and Lactobacillus casei subsp. pseudoplantarum DSM $20008^{T}$ were the type strains most closely related to the $L$. reuteri SIMCA class. The $L$. reuteri strains isolated from rats could be separated from the $L$. reuteri strains isolated from humans and pigs by the PCA. DNA-DNA-hybridization showed that strains classified as $L$. reuteri on the basis of the results of the restriction enzyme analysis also exhibited $>70 \%$ DNA-DNAhomology to the type strain of $L$. reuteri. The phenotype of $L$. reuteri (ability to ferment carbohydrates) coincided in most cases with the genotype; this seemed not to be the case for $L$. fermentum strains.
\end{abstract}

The genus Lactobacillus, which contains more than 70 species, is by tradition phenotypically founded, and the different species are grouped together on the basis of their metabolic pathways (12). However, from a genetic perspective the genus is heterogeneous because the $\mathrm{G}+\mathrm{C}$ contents range from 30 to $55 \mathrm{~mol} \%$, and comparisons of $16 \mathrm{~S}$ rRNAs have revealed relationships between different species which are not consistent with the traditional metabolic groups (8). Several of the traditional phenotypic traits used for species characterization in the genus Lactobacillus are unstable and uncertain $(1 \mathrm{a}, 5)$. Thus, a genotypically based classification of Lactobacillus strains, both above and below the species level, is urgently needed. One approach is to use restriction endonuclease analysis (REA) and chromosomal DNAs (17), which is feasible since REA gels can be numerically analyzed for similarity. This can be done either by a more traditional numerical analysis or by principal-component analysis (PCA).

Lactobacillus reuteri, which is an obligatory heterofermentative bacterium, was first described by Kandler et al. (11). Isolates having the $L$. reuteri phenotype are frequently found associated with the gastrointestinal tracts of humans $(12,13)$ and animals $(2,14)$. Industrial interest in $L$. reuteri is increasing as it has been proved that some strains can produce an antimicrobial compound called reuterin $(4,7)$. A commercial milk product based on $L$. reuteri ("BRA-milk") was introduced in Sweden in 1991. Furthermore, a Lacto-

\footnotetext{
* Corresponding author. Mailing address: Department of Food Technology, P.O. Box 124, S-221 00 Lund, Sweden. Fax: 4646109517 .
}

bacillus strain that was isolated from rats and was identified phenotypically as $L$. reuteri (strain R2LC) (14) hindered acetic acid-induced colitis in rats (10).

The aims of this study were to use REA for the classification of strains that had been phenotypically identified as $L$. reuteri and to compare these strains with other heterofermentative field strains having a similar phenotype (Lactobacillus fermentum) and with some type strains of organisms belonging to different catabolic categories. The classification obtained was compared with the results of a DNA-DNA homology study.

\section{MATERIALS AND METHODS}

Strains and culture conditions. The strains which we tested are listed in Table 1 . In addition, $L$. reuteri N4I (representing 20 identical isolates) (14) was also tested. The field strains isolated from humans, pigs, and rats were all phenotypically identified as either $L$. reuteri or $L$. fermentum on the basis of the results of API $50 \mathrm{CH}$ tests (API Systems S.A., Montalieu Vercieu, France). The strains were grown at $37^{\circ} \mathrm{C}$ in Lactobacillus carrying medium (9) containing 0.3 to $1 \%$ glucose. Stock cultures were stored at $-80^{\circ} \mathrm{C}$ in freezing buffer (1a).

Preparation and agarose gel electrophoresis of plasmid DNAs. Plasmid DNAs were prepared from strains 2DS20057:R, 8704:3, 1044, 8557:1, 1068, 8557:3, 8581:1, and $8580: 3$ (6) and were electrophoresed in $0.7 \%$ agarose gels together with Escherichia coli V517 reference plasmids (Plasmid Reference Center, Stanford, Calif.). The gels were electrophoresed for $4 \mathrm{~h}$ at $120 \mathrm{~V}$ in TB electrophoresis buffer ( $89 \mathrm{mM}$ boric acid, $23 \mathrm{mM} \mathrm{H} \mathrm{PO}_{4}, 2.5$ mM EDTA; pH 8.3) after an initial run at $12 \mathrm{~mA}$. 
TABLE 1. Clusters of Lactobacillus strains obtained at an $S_{J}$ similarity level of $69 \%$ by using the UPGMA method ${ }^{a}$

\begin{tabular}{|c|c|c|c|c|c|c|c|}
\hline \multirow[b]{2}{*}{ Cluster } & \multirow{2}{*}{$\underset{(\%)^{b}}{\text { Similarity level }}$} & \multirow[b]{2}{*}{ Strain } & \multirow{2}{*}{$\begin{array}{c}\text { Source } \\
\text { of } \\
\text { isolation }\end{array}$} & \multirow{2}{*}{$\begin{array}{l}\text { Culture } \\
\text { no. }^{c}\end{array}$} & \multicolumn{3}{|c|}{ Similarity distance from ${ }^{d}$} \\
\hline & & & & & $\begin{array}{l}\text { Strain } \\
1073\end{array}$ & $\begin{array}{l}\text { Strain } \\
\text { R2J }\end{array}$ & $\begin{array}{c}\text { Strain DSM } \\
20016^{\mathrm{T}}\end{array}$ \\
\hline 1a & 77 & L. reuteri 1073 & Pig $^{e}$ & 1 & 0 & 26 & 24 \\
\hline 1a & & L. reuteri $\mathrm{N} 5 \mathrm{D}: 1$ & Rat $^{f}$ & 11 & 16 & 23 & 30 \\
\hline 1a & & L. reuteri 1068 & Pige & 2 & 18 & 28 & 30 \\
\hline 1a & & L. reuteri $8557: 3(108)^{g}$ & Human $^{h}$ & 5 & 21 & 32 & 33 \\
\hline la & & L. reuteri 1063 & Pig $^{e}$ & 3 & 16 & 30 & 29 \\
\hline $1 b$ & 76 & L. reuteri 1048 & Pig $^{e}$ & 14 & 24 & 27 & 28 \\
\hline $1 b$ & & Lactobacillus sp. strain DSM 20056 & & 34 & 28 & 32 & 35 \\
\hline $1 \mathrm{c}$ & 76 & L. reuteri $\mathrm{N} 2 \mathrm{~J}^{i}$ & $\mathrm{Rat}^{f}$ & 7 & 26 & 0 & 36 \\
\hline lc & & L. reuteri $\mathrm{N}^{2} \mathrm{D}^{\mathrm{j}}$ & Rat $^{f}$ & 8 & 22 & 17 & 30 \\
\hline lc & & L. reuteri N5LC: $2^{k}$ & Rat $^{f}$ & 12 & 26 & 26 & 35 \\
\hline $1 \mathrm{c}$ & & L. reuteri $\mathrm{R} 2 \mathrm{LC}{ }^{l}$ & $\mathrm{Rat}^{f}$ & 9 & 23 & 26 & 31 \\
\hline $1 \mathrm{~d}$ & 69 & L. reuteri DSM $20016^{\mathrm{T}}$ & & 19 & 24 & 36 & 0 \\
\hline None & $68^{m}$ & L. reuteri DSM 20015 & $f, h$ & 20 & 29 & 30 & 40 \\
\hline None & & L. helveticus DSM $20075^{\mathrm{T}}$ & & 33 & 36 & 31 & 37 \\
\hline 2 & 91 & L. reuteri $8557: 1$ & Human ${ }^{n}$ & 4 & 28 & 43 & 39 \\
\hline 2 & & L. reuteri 1044 & Pig $^{e}$ & 13 & 29 & 42 & 36 \\
\hline 3 & 85 & L. reuteri $8580: 3$ (133) & Human $^{h}$ & 6 & 33 & 44 & 40 \\
\hline 3 & & L. fermentum 8581:1 (134) & Human $^{h}$ & 15 & & & \\
\hline None & & L. fermentum 8607:2 (142) & Human $^{h}$ & 16 & & & \\
\hline $4 a$ & 79 & L. fermentum $8690: 1$ & Human $^{n}$ & 17 & & & \\
\hline $4 a$ & & L. casei subsp. pseudoplantarum DSM $20008^{\mathrm{T}}$ & & 29 & & & \\
\hline $4 \mathrm{~b}$ & 72 & Lactobacillus brevis DSM $20054^{\mathrm{T}}$ & & 26 & & & \\
\hline $4 b$ & & L. casei subsp. casei DSM $20011^{\mathrm{T}}$ & & 30 & & & \\
\hline $4 \mathrm{~b}$ & & L. fermentum ATCC $14931^{\mathrm{T}}$ & & 32 & & & \\
\hline $4 \mathrm{~b}$ & & L. rhamnosus DSM $20021^{\mathrm{T}}$ & & 31 & & & \\
\hline $4 c$ & 95 & L. fermentum $8704: 3(245)$ & $-h$ & 18 & & & \\
\hline $4 c$ & & L. fermentum 2DS20057:R $(16)^{\circ}$ & $-^{n}$ & 23 & & & \\
\hline 5 & 72 & L. plantanum ATCC $14917^{\mathrm{T}}$ & & 21 & & & \\
\hline 5 & & L. plantarum ATCC 8014 & $-^{h}$ & 22 & & & \\
\hline None & & Lactobacillus crispatus DSM $20584^{\mathrm{T}}$ & & 25 & & & \\
\hline 6 & 69 & Lactobacillus hamsteri ATCC $43851^{\mathrm{T}}$ & & 24 & & & \\
\hline 6 & & Lactobacillus amylovorus DSM $20531^{\mathrm{T}}$ & & 27 & & & \\
\hline None & & Lactobacillus alimentarius DSM $20249^{\mathbf{T}}$ & & 28 & & & \\
\hline
\end{tabular}

a DSM, Deutsche Sammlung von Mikroorganismen, Göttingen, Germany; ATCC, American Type Culture Collection, Rockville, Md.

${ }^{b}$ The similarity level at which the strains of a cluster or subcluster merge.

c Culture numbers used in Fig. 1 and 2 for indicating strains.

${ }^{d}$ Similarity distances $\left(D_{J}\right)$ between strains were calculated by using the following formula: $D_{J}=100\left(1-S_{J}\right)$.

Isolated and described by Axelsson and Lindgren (3).

${ }^{f}$ Phenotypically characterized by Molin et al. (14).

$g$ The numbers in parentheses are the designations used by Molin et al. (13).

${ }^{h}$ Phenotypically characterized by Molin et al. (13) (cluster 13, which was labeled Lactobacillus buchneri).

${ }^{i}$ Represents four isolates having identical REA patterns.

${ }^{j}$ Represents three isolates having identical REA patterns.

${ }^{k}$ Represents two isolates having identical REA patterns.

${ }^{l}$ Represents 12 isolates having identical REA patterns.

${ }^{m} L$. reuteri DSM 20015 merges with cluster 1 at a similarity level of $68 \%$.

${ }^{n}$ Phenotypically characterized by Molin et al. (13), but the phenotype is not shown in the results.

${ }^{\circ}$ L. fermentum 2DS20057:R was phenotypically characterized by Molin et al. (13) and was assumed to be Lactobacillus buchneri DSM 20057 ${ }^{\mathrm{r}}$; strain 2DS20057:R was later assigned to $L$. fermentum by workers in our laboratory on the basis of a partially identical 16S rRNA sequence and $>70 \%$ DNA-DNA-homology to L. fermentum ATCC $14931^{\mathrm{T}}$ (1).

Restriction endonuclease digestions. Chromosomal DNAs were prepared and cleaved by restriction endonucleases as previously described (17). Aliquots (750 ng) of DNA were digested with Asp 718, EcoRI, and ClaI and were electrophoresed in agarose gels. The DNA concentrations were determined with a fluorometer (model TKO 100; Hoefer Scientific Instruments, San Fransisco, Calif.).

Electrophoresis and scanning of gels. Agarose gel electrophoresis of chromosomal DNA was performed as described by Ståhl et al. (17). The band patterns of the REA gels were 


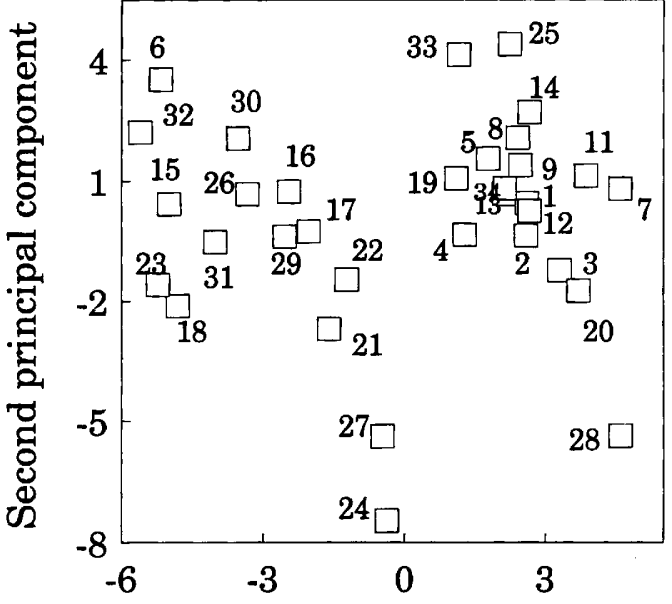

First principal component

FIG. 1. First and second principal-component scores obtained for the projection based on the complete data set (except the data for L. reuteri N4I). The strains used and their culture numbers are listed in Table 1 . The axes are in arbitrary units.

scanned with a laser densitometer (UltroScan XL; Pharmacia LKB Biotechnology AB, Uppsala, Sweden), and the resulting absorbance curves were transformed into data sets by using the method of Ståhl et al. (17). Each lane was scanned three times, and the mean value for the relative absorbance in each interval was computed. The absorbance curves obtained with $C l a I$ and EcoRI digests were each divided into 20 intervals, and the curves obtained with $A s p$ 718 digests were each divided into 40 intervals. The recorded band patterns gave a data set consisting of 34 objects (strains) and 80 variables (total relative peak areas of absorbance intervals). In some cases plasmid bands interfered with the recording of the chromosomal band patterns, and the variable was then defined as missing. The DNA of strain N4I was resistant to ClaI digestion, and the data for all of the variables from ClaI digestion of the DNA of $L$. reuteri $\mathrm{N} 4 \mathrm{I}$ were considered missing data.

Mathematical analyses. The data set was numerically analyzed by using the Jaccard coefficient $\left(S_{J}\right)(16)$, and clustering was accomplished by using the unweighted pair group method with arithmetic averages (UPGMA) (15). The UPGMA values were calculated for the complete data set (except the data for strain N4I), and the CLUSTAN 2 program (release 3.2; D. Wishart, Program Library Unit, Edinburgh University) was used. The values used for variables for which there were no data were the mean values of the variables for all strains. Similarity distances $\left(D_{J}\right)$ between strains were calculated $\left[D_{J}=100\left(1-S_{J}\right)\right]$.

The SIMCA-3B program (version TMP; Sepanova AB, Enskede, Sweden) was used for PCA and soft independent modeling of class analogy (SIMCA) of the data set. A PCA was performed with the complete data set (except the data for strain N4I) without direct reference to class separation (Fig. 1). The values used for variables for which there were no data were the mean values of the variables for all strains.

SIMCA was used to classify the isolates and to investigate the distances between different type strains belonging to a select group (labeled "class" in the SIMCA manual) of $L$. reuteri. A class model (Table 2) was constructed with the 12 isolates that clustered together with the $L$. reuteri type strain
TABLE 2. Residual standard deviation to the class model of $L$. reuteri ${ }^{a}$

\begin{tabular}{|c|c|}
\hline Strain & $\begin{array}{c}\text { Residual standard } \\
\text { deviation }\end{array}$ \\
\hline L. reuteri $\mathrm{R} 2 \mathrm{LC}$ & $0.478^{b}$ \\
\hline L. reuteri $1044 \ldots$ & $0.591^{b}$ \\
\hline L. reuteri $1068 \ldots . . .$. & $0.676^{b}$ \\
\hline 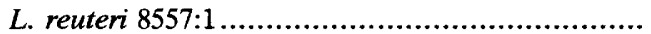 & $0.751^{b}$ \\
\hline L. reuteri $\mathrm{N} 2 \mathrm{~J}$......... & $0.752^{b}$ \\
\hline L. reuteri $1073 \ldots . .$. & $0.808^{b}$ \\
\hline L. reuteri $8557: 3$... & $0.851^{b}$ \\
\hline L. reuteri $1048 \ldots$. & $0.918^{b}$ \\
\hline L. reuteri N5LC: 2 .. & $0.975^{b}$ \\
\hline L. reuteri $1063 \ldots . .$. & $1.01^{b}$ \\
\hline L. reuteri $\mathrm{N} 5 \mathrm{D}: 1 \ldots$. & $1.02^{b}$ \\
\hline 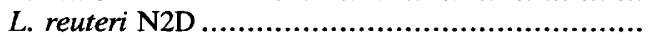 & $1.10^{b}$ \\
\hline L. reuteri $\mathrm{N} 4 \mathrm{I} \ldots$ & $1.06^{c}$ \\
\hline L. reuteri DSM $20016^{\mathrm{T}}$. & $1.33^{c}$ \\
\hline Lactobacillus sp. strain DSM $20056 \ldots \ldots \ldots \ldots \ldots \ldots$ & $1.34^{c}$ \\
\hline 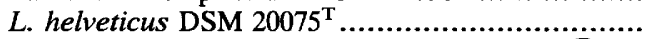 & 1.47 \\
\hline L. casei subsp. pseudoplantarum DSM $20008^{\mathrm{T}} \ldots .$. & 1.50 \\
\hline 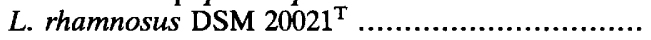 & 1.53 \\
\hline L. fermentum $8690: 1 \ldots \ldots \ldots$. & 1.54 \\
\hline L. casei subsp. casei DSM $20011^{\mathrm{T}}$. & 1.57 \\
\hline L. plantarum ATCC $14917^{\mathrm{T}} \ldots \ldots \ldots \ldots$ & 1.63 \\
\hline 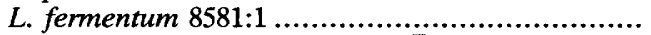 & 1.72 \\
\hline Lactobacillus brevis DSM $20054^{\mathrm{T}} \ldots \ldots$. & 1.83 \\
\hline Lactobacillus crispatus DSM $20584^{\mathrm{T}}$.. & 1.83 \\
\hline "L. reuteri" $8580: 3 . . . .$. & 1.84 \\
\hline L. fermentum $8607: 2 \ldots$ & 1.84 \\
\hline Lactobacillus hamsteri ATCC $43851^{\mathrm{T}}$.. & 1.85 \\
\hline 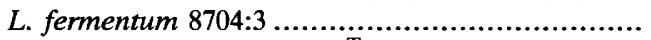 & 1.88 \\
\hline L. fermentum ATCC $14931^{\mathrm{T}} \ldots \ldots$. & 1.91 \\
\hline L. fermentum 2DS20057:R .... & 2.12 \\
\hline L. plantarum ATCC $8014 \ldots . .$. & 2.18 \\
\hline 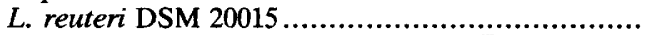 & 2.31 \\
\hline Lactobacillus amylovorus DSM $20531^{\mathrm{T}}$................ & 2.64 \\
\hline Lactobacillus alimentarius DSM $20249^{\mathrm{T}} \ldots \ldots \ldots \ldots \ldots$ & 2.82 \\
\hline
\end{tabular}

${ }^{a}$ The pooled RSD of the class is 1.14 .

${ }^{b}$ Strains used for construction of the class model. The values were corrected for loss of degrees of freedom.

${ }^{c}$ Strains belonging to the class with a $99 \%$ confidence limit according to the F-test.

in the initial PCA, and this set of isolates exhibited 80 variables. A total of 15 variables were technically unreliable or missing and were defined as "missing values" (these values were representative of the mean values of the variables for strains in the class). All of the strains were subjected to an F-test, in which the residual variance of each strain in the whole group was compared with the pooled residual variances of the strains in the class model; the square of the pooled residual variance was defined as the sum of all squared variances divided by the number of objects. When strains were tested with the class model, no missing data had to be filled in with approximate values since missing values do not interfere with SIMCA.

An additional PCA was performed with the strains used in the class model, together with $L$. reuteri DSM $20016^{\mathrm{T}}$ (T = type strain), L. reuteri DSM 20015, and Lactobacillus sp. strain DSM 20056 (Fig. 2). The values used for the missing variables were the mean values of the variables for all of the strains.

Nonradioactive labeling of DNA. Portions $(1 \mu \mathrm{g})$ of chromosomal DNAs from $L$. reuteri DSM $20016^{\mathrm{T}}, 1073$, and N2J were sheared by sonication (model 250 Sonifier; Branson Ultrasonics Corp., Danbury, Conn.) for eight 30-s periods. 


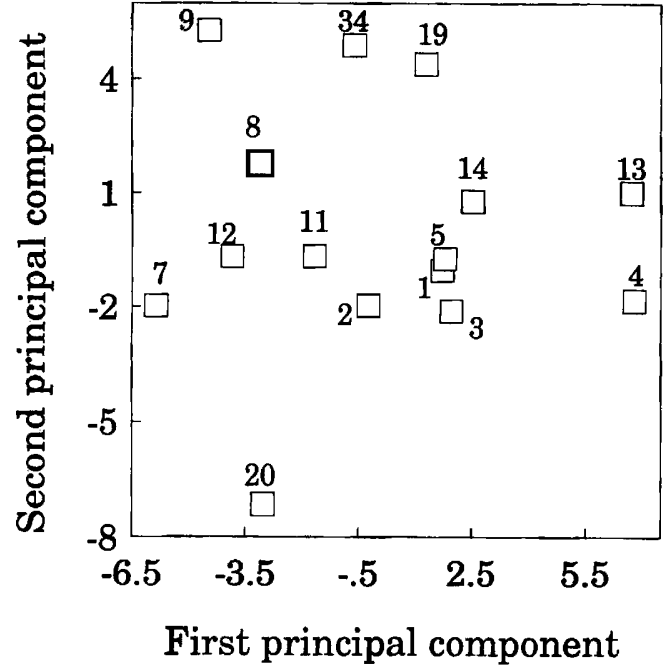

FIG. 2. First and second principal-component scores obtained for the projection based on the 12 strains used for the $L$. reuteri class model together with $L$. reuteri DSM $20016^{\mathrm{T}}$, Lactobacillus sp. strain DSM 20056, and $L$. reuteri DSM 20015. The strains used and their culture numbers are listed in Table 1 . The axes are in arbitrary units.

The fragment sizes were determined to be approximately 0.4 $\mathrm{kb}$ by gel electrophoresis. Each sheared DNA was labeled with digoxygenin (DIG-DNA labeling and detection kit; Boehringer Mannheim Scandinavia AB, Bromma, Sweden) for $18 \mathrm{~h}$ according to the instructions of the manufacturer.

DNA-DNA hybridization. Hybridization reactions and washing and detection steps were performed by using the reagents in the DIG-DNA labeling and detection kit according to the instructions of the manufacturer (Boehringer Mannheim Scandinavia AB). Chromosomal DNAs from 10 strains were diluted in TE (10 mM Tris, $1 \mathrm{mM}$ EDTA; $\mathrm{pH}$ 8.0). The DNAs were immobilized on a positively charged nylon membrane (Boehringer Mannheim Scandinavia AB) by filtration in a Minifold apparatus (type SRC 96; Schleicher \& Schuell, Inc., Keene, N. H.) and subsequent baking at $120^{\circ} \mathrm{C}$ for $20 \mathrm{~min}$. Aliquots $(75 \mu \mathrm{l})$ of each DNA concentration $(50,25,12.5,6.25$, and $3.125 \mathrm{ng} / 75 \mu \mathrm{l})$ from each strain were filtered, and the wells were then washed once with 150 $\mu l$ of TE. The DNA was only loaded in every second well in order to avoid the hybridization signals from neighboring wells interfering with each other. Four parallel membranes containing immobilized DNA were prepared. Two membranes were hybridized with a digoxygenin-labeled $L$. reuteri DSM $20016^{\mathrm{T}}$ DNA probe, and the other two membranes were hybridized with digoxygenin-labeled DNAs from strains 1073 and N2J (one membrane was hybridized with strain 1073 DNA and one membrane was hybridized with strain N2J DNA). The membranes were hybridized for $18 \mathrm{~h}$ at $64^{\circ} \mathrm{C}$. The digoxygenin-labeled probes were detected with anti-digoxigenin antibody Fab fragments conjugated to alkaline phosphatase. The dephosphorylation of the chemiluminescent substrate Lumigen PPD generated light, which was documented on Kodak X-OMAT AR film during 2 min of exposure to the membranes.

The X-ray films were scanned two dimensionally with a laser densitometer (UltroScan XL; Pharmacia LKB Biotechnology $A B$ ), and the data were processed by using the LKB 2400 GelScan XL program (Pharmacia LKB Biotechnology AB). The total density of each spot was recorded.
TABLE 3. Filter hybridization at the "optimal" temperature with nonradioactivity labeled DNA

\begin{tabular}{|c|c|c|c|}
\hline \multirow{2}{*}{ DNA on filter } & \multicolumn{3}{|c|}{$\begin{array}{l}\text { \% DNA-DNA homology with labeled } \\
\text { DNA from: }\end{array}$} \\
\hline & $\begin{array}{l}\text { Strain DSM } \\
20016^{\mathbf{T}}\end{array}$ & $\begin{array}{c}\text { Strain } \\
1073\end{array}$ & $\begin{array}{l}\text { Strain } \\
\text { N2J }\end{array}$ \\
\hline $\begin{array}{l}\text { L. reuteri DSM } 20016^{\mathrm{T}} \\
\text { L. reuteri DSM } 20015 \\
\text { Lactobacillus } \mathrm{sp} \text {. strain } \\
\quad \text { DSM } 20056\end{array}$ & $\begin{array}{l}100 \\
93 \pm 5 \\
75 \pm 5\end{array}$ & $\begin{array}{l}86 \pm 10^{a} \\
77 \pm 5 \\
56 \pm 10\end{array}$ & $\begin{array}{l}80 \pm 5 \\
65 \pm 5 \\
58 \pm 5\end{array}$ \\
\hline $\begin{array}{l}\text { L. reuteri } 1044 \\
\text { L. reuteri } 1073 \\
\text { L. reuteri } 1063 \\
\text { L. reuteri N2J } \\
\text { L. reuteri } \mathrm{R} 2 \mathrm{LC} \\
\text { L. reuteri N5D:1 } \\
\text { L. fermentum ATCC } 14931^{\mathrm{T}} \\
\text { L. casei subsp. } \\
\text { pseudoplantarum }\end{array}$ & $\begin{aligned} 77 & \pm 5 \\
84 & \pm 5 \\
70 & \pm 5 \\
89 & \pm 5 \\
80 & \pm 5 \\
80 & \pm 10 \\
34 & \pm 10 \\
5 & \pm 5\end{aligned}$ & $\begin{array}{l}84 \pm 5 \\
100 \\
90 \pm 5 \\
83 \pm 10 \\
81 \pm 5 \\
80 \pm 5 \\
25 \pm 10\end{array}$ & $\begin{array}{l}68 \pm 5 \\
80 \pm 5 \\
74 \pm 5 \\
100 \\
89 \pm 5 \\
84 \pm 5 \\
29 \pm 10\end{array}$ \\
\hline
\end{tabular}

a Percentage of hybridization \pm estimated margin of error based on the range of variation obtained in replicate hybridizations of homologous DNA (L. reuteri DSM $20016^{\mathrm{T}}$ ).

The levels of DNA-DNA-homology were calculated from direct plots of absorption versus DNA concentration. The final level of reassociation (or homology) was defined as the ratio of the maximum density of a tested DNA to the saturation density of the probe DNA. A plot of the homology values (including reference values) versus logarithmic values for the initial reassociation ratios (defined as the initial slope from the saturation plots) resulted, in most cases, in a linear relationship. When the calculated levels of homology were not proportional to the initial reassociation values, the homology value was defined as the average of the results of the two calculations (these homology values were assigned a larger margin of error) (Table 3). Deviations were assumed to result from the facts that (i) at lower levels of homology final saturation densities were not reached at the corresponding DNA concentrations, and (ii) different regions of the chromosomal DNA might exhibit different levels of homology. The experimental margin of error was estimated from the results of two independent experiments by using DNA from $L$. reuteri DSM $20016^{\mathrm{T}}$ as a probe.

\section{RESULTS}

$S_{J}$-based UPGMA. The $S_{J}$-based cluster analysis identified six clusters, which were defined at a similarity level of $69 \%$ (Table 1).

Cluster 1 comprised 10 field isolates (all originally identified as $L$. reuteri), Lactobacillus sp. strain DSM 20056, and L. reuteri DSM $20016^{\mathrm{T}}$ and could be divided into four subclusters. The type strain formed a one-member cluster that merged with the other strains at a similarity level of $69 \%$ (Table 1). The straggling strain L. reuteri DSM 20015 merged with cluster 1 at a similarity level of $68 \%$.

Cluster 2 included two field strains phenotypically identified as $L$. reuteri (Table 1 ).

Cluster 3 included two field strains phenotypically identified as $L$. reuteri and $L$. fermentum (Table 1 ).

Cluster 4 comprised two field strains, one reference strain, and five different type strains and could be divided into three subclusters (Table 1). Subcluster $4 a$ included one field strain labeled L. fermentum and Lactobacillus casei subsp. pseudoplantarum DSM $200008^{\mathrm{T}}$; subcluster $4 \mathrm{~b}$ included the 
type strain of $L$. fermentum and three additional type strains; and subcluster $4 \mathrm{c}$ consisted of one field strain phenotypically identified as $L$. fermentum and $L$. fermentum 2DS20057:R.

Cluster 5 contained two Lactobacillus plantarum strains, one of which was the type strain (Table 1).

Cluster 6 included two type strains (Table 1).

PCA-SIMCA results. The PCA of the complete data set (except the data for strain N4I) resulted in the a loading plot of the first and second principal components (Fig. 1). The loading plot showed that all of the phenotypically identified $L$. reuteri strains (except strain 8580:3) formed a group with L. reuteri DSM $20016^{\mathrm{T}}$ (plus $L$. reuteri DSM 20015 and Lactobacillus sp. strain DSM 20056). This group was well separated from all other strains (Fig. 1).

L. fermentum 8704:3 and 2DS20057:R were closely related, differing only in one band on the REA gels (Fig. 1).

All of the strains were tested with a class model constructed by the SIMCA method from the $L$. reuteri labeled field strains shown in Fig. 1 (Table 2). L. reuteri N4I and DSM $20016^{\mathrm{T}}$ and Lactobacillus sp. strain DSM 20056 belonged to the class with a confidence limit of $99 \%$, but all of the other strains outside the class reference set, as well as $L$. reuteri DSM 20015, were excluded by the model (Table 2 ). With the exception of $L$. reuteri $\mathrm{R} 2 \mathrm{LC}$, the different strains belonging to the class reference set could be omitted during class construction (one by one), but they still fitted the class (data not shown). L. reuteri $\mathrm{R} 2 \mathrm{LC}$ only fitted the class when it had been included in the reference set.

According to the SIMCA class model, the type strains most closely related to $L$. reuteri were Lactobacillus helveticus DSM 20075, L. casei subsp. pseudoplantarum DSM 20008, Lactobacillus rhamnosus DSM 20021, and Lactobacillus casei subsp. casei DSM 20011 (Table 2).

The results of a second PCA, which included only the strains belonging to the class model (Table 2) and $L$. reuteri DSM $20016^{\mathrm{T}}$, L. reuteri DSM 20015, and Lactobacillus sp. strain DSM 20056, are shown in Fig. 2. The first principal component separated the strains isolated from rats from the other isolates. The second principal component singled out L. reuteri DSM 20015.

Plasmid profiles. Eight strains produced four pairs of almost identical REA patterns in which the members of each pair differed in only one to three bands. Plasmid profiles were obtained for these eight strains. The pair consisting of L. fermentum 2DS20057:R and 8704:3 appeared to be plasmid free. $L$. reuteri 1044 and 8557:1 harbored three plasmids whose sizes were the same in the two strains $(5.4 \pm 0.3,7.1$ \pm 0.4 , and $37 \pm 2 \mathrm{MDa})$. $L$. fermentum $8581: 1$ and " $L$. reuteri' $8580: 3$ contained two plasmids whose sizes were the same in the two strains $(1.2 \pm 0.06$ and $5.4 \pm 0.3 \mathrm{MDa})$. And L. reuteri 1068 and 8557:3 contained five plasmids whose sizes were the same in the two strains $(2.6 \pm 0.1,5.4 \pm 0.3$, $7.1 \pm 0.4,25.3 \pm 1.3$, and $32 \pm 2 \mathrm{MDa})$, but in addition $L$. reuteri 1068 contained two other plasmids $(5.1 \pm 0.3$ and 18.2 $\pm 1 \mathrm{MDa}$ ).

DNA-DNA hybridization. The results of hybridization of chromosomal DNAs from some of the strains to DNAs from L. reuteri DSM $20016^{\mathrm{T}}, 1073$, and $\mathrm{N} 2 \mathrm{~J}$ are shown in Table 3. The type strain exhibited the highest level of similarity to $L$. reuteri DSM 20015 and a similarity level of $70 \%$ or more to all of the field strains tested. L. reuteri 1073 exhibited the highest levels of homology to the type strain and the two field strains isolated from pigs tested and also exhibited relatively high levels of homology to the other $L$. reuteri strains (Table 3 ). $L$. reuteri $\mathrm{N} 2 \mathrm{~J}$ exhibited the highest levels of homology to the field strains isolated from rats and a relatively low level of homology to strain $1044(68 \%)$. The levels of homology to L. fermentum ATCC $14931^{\mathrm{T}}$ were low (Table 3).

\section{DISCUSSION}

The phenotypic approach to Lactobacillus taxonomy has been challenged $(1 \mathrm{a}, 5)$. However, in the case of $L$. reuteri, our data indicate that the genotype reflects the phenotype (that is, the ability to ferment different carbohydrates in API $50 \mathrm{CH}$ tests), even if there is one striking exception, " $L$. reuteri"' 8580:3 (Table 1 and Fig. 1).

The two different numerical models used for comparisons of the restriction patterns gave similar results. However, the PCA-SIMCA model (Fig. 1 and 2) resulted in a better understanding of the relationships among the strains. For example, when the UPGMA model was used, L. reuteri 1044 and 8557:1 were members of a single cluster (Table 1 , cluster 2 ), widely separated from the major $L$. reuteri cluster (cluster 1). Even if these two strains were also separated by the PCA, the SIMCA class model clearly demonstrated that they were very similar to the other strains of L. reuteri (Table 2). This similarity was also confirmed by the DNA-DNA homology data (Table 3).

Another advantage of SIMCA is the ability to handle missing values. The values for ClaI digests were missing from the $L$. reuteri $N 4$ I data set. Therefore, the strain could not be processed by the UPGMA method but could be included in the SIMCA analysis (Table 2).

Dye-buoyant density centrifugation separates covalently closed circular plasmid DNA from chromosomal DNA, but open circular and linear forms of large plasmids may contaminate the preparation and obstruct the interpretation of the REA band patterns. However, with the PCA-SIMCA method it is possible to spot bands which may be of plasmid origin (17). It can also be pointed out that the plasmid profiles were similar for the four pairs of closely related strains found in this study, which may suggest that the few distinguishing REA bands in these cases were not of plasmid origin.

The REA classification determined in this study might, at first glance, give the impression that there is a relatively heterogeneous group of $L$. reuteri strains (Table 1 and Fig. 1 and 2). However, the $L$. reuteri strains were separated from other strains, and DNA-DNA-hybridizations showed that the $L$. reuteri strains exhibited levels of homology of $70 \%$ or more to the type strain (Table 3 ). Thus, the REA and DNA-DNA homology data are in general agreement.

The only major discrepancy between the DNA-DNA homology data and the REA data was observed with $L$. reuteri DSM 20015. In the REA this strain was excluded from $L$. reuteri (Tables 1 and 2), while its level of DNA-DNA homology to $L$. reuteri DSM $20016^{\mathrm{T}}$ was $93 \%$ (Table 3 ), which is consistent with the data of Vescovo et al. (18).

It may seem anomalous that the type strain of $L$. fermentum exhibits $34 \%$ DNA-DNA homology to the type strain of L. reuteri (Table 3 ) when the $\mathrm{G}+\mathrm{C}$ contents of these strains differ by about $10 \mathrm{~mol} \%$. However, this level of homology may be due to the high $\mathrm{G}+\mathrm{C}$ content ( 52 to $54 \mathrm{~mol} \%$ [thermal denaturation method]) of $L$. fermentum and to the fact that the hybridization reaction was performed at $64^{\circ} \mathrm{C}$. REA data place $L$. fermentum ATCC $14931^{\mathrm{T}}$ far from the $L$. reuteri strains in the multidimensional space diagram.

Lactobacillus sp. strain DSM 20056 exhibited 75\% DNADNA homology to the type strain of $L$. reuteri but was previously reported to have a DNA-DNA homology level of 
less than $70 \%$ (18); the discrepancy in these values might be because the former value was obtained in an experiment that was not performed at the "stringent" temperature.

REA combined with numerical analyses has a potential for effective assessment of relationships on the species level. Furthermore, REA groups biovariants and detects individual strains at a level far below the species level. However, a crucial question is to what extent the relationships between the $L$. reuteri cluster and the most closely related surrounding strains should be trusted. For example, is $L$. reuteri more closely related to $L$. helveticus and $L$. casei subsp. pseudoplantarum than to the other type strains tested (Fig. 1 and Table 2)?

Can REA be used to determine relationships above the species level? This question may be answered by using SIMCA with an expanded data set in which each species is described by its "own" class model. Then the distances between the species (class models) can be calculated. However, the question can be answered only by comparing REA results with the results of other methods. Nevertheless, it should be pointed out that the type strains of the related taxa L. casei subsp. pseudoplantarum, L. rhamnosus (formerly $L$. casei subsp. rhamnosus), and $L$. case $i$ subsp. casei merged in the SIMCA class model (Table 3).

\section{ACKNOWLEDGMENTS}

We thank Marie Kala for her skillful technical assistance and Siv Ahrné for valuable discussions.

This work was supported by The Swedish Council for Forestry and Agricultural Research and the Swedish Natural Science Research Council.

\section{REFERENCES}

1. Ahrné, S. Personal communication.

1a.Ahrné, S., and G. Molin. 1991. Spontaneous mutations changing the raffinose metabolism of Lactobacillus plantarum. Antonie van Leeuweenhoek 60:87-93.

2. Axelsson, L. 1990. Lactobacillus reuteri, a member of the gut bacterial flora. Ph.D. thesis. Swedish University of Agricultura Sciences Department of Microbiology Report 44. SLU/Repo, Uppsala, Sweden.

3. Axelsson, L., and S. Lindgren. 1987. Characterization and DNA homology of Lactobacillus strains isolated from pig intestine. J. Appl. Bacteriol. 62:433-440.

4. Axelsson, L. T., T. C. Chung, W. J. Dobrogosz, and S. Lindgren. 1989. Production of broad spectrum antimicrobial substance by Lactobacillus reuteri. Microb. Ecol. Health Dis. 2:131-136.

5. Borch, E., and G. Molin. 1988. Numerical taxonomy of psychro- trophic lactic acid bacteria from prepacked meat and meat products. Antonie van Leeuwenhoek 54:301-323.

6. Chassy, B. M., E. M. Gibson, and A. Giuffrida. 1976. Evidence for extrachromosomal elements in Lactobacillus. J. Bacteriol. 127:1576-1578.

7. Chung, T. C., L. Axelsson, S. E. Lindgren, and W. J. Dobrogosz. 1989. In vitro studies on reuterin synthesis by Lactobacillus reuteri. Microb. Ecol. Health Dis. 2:137-144.

8. Collins, M. D., U. Rodrigues, C. Ash, M. Aguirre, J. A. E. Farrow, A. Martinez-Murcia, B. A. Phillips, A. M. Williams, and S. Wallbanks. 1991. Phylogenetic analysis of the genus Lactobacillus and related lactic acid bacteria as determined by reverse transcriptase sequencing of 16S rRNA. FEMS Microbiol. Lett. 7:5-12.

9. Efthymiou, C., and P. A. Hansen. 1962. An antigenic analysis of Lactobacillus acidophilus. J. Infect. Dis. 110:258-267.

10. Fabia, R., A. Ar'Rajab, M.-L. Johansson, R. Willén, R. Andersson, G. Molin, and S. Bengmark. 1993. The effect of exogenous administration of Lactobacillus reuteri R2LC and oat fiber on acetic acid-induced colitis in the rat. Scand. J. Gastroenterol. 28:155-162.

11. Kandler, O., K.-O. Stetter, and R. Köhl. 1980. Lactobacillus reuteri $\mathrm{sp}$. nov., a new species of heterofermentative lactobacilli. Zentralbl. Bakteriol. Microbiol. Hyg. Abt. 1 Orig. Reihe C 1:264-269.

12. Kandler, O., and N. Weiss. 1986. Regular, non-sporing Grampositive rods, p. 1208-1234. In P. H. A. Sneath, N. S. Mair, M. E. Sharpe, and J. G. Holt (ed.), Bergey's manual of systematic bacteriology, vol. 2. Williams \& Wilkins, Baltimore.

13. Molin, G., B. Jeppsson, S. Ahrné, M.-L. Johansson, S. Nobaek, M. Ståhl, and S. Bengmark. 1993. Numerical taxonomy of Lactobacillus spp. associated to healthy and diseased mucosa of the human intestines. J. Appl. Bacteriol. 74:314-323.

14. Molin, G., M.-L. Johansson, M. Ståhl, S. Ahrné, R. Andersson, B. Jeppsson, and S. Bengmark. 1992. Systematics of the Lactobacillus population on rat intestinal mucosa with special reference to Lactobacillus reuteri. Antonie van Leeuwenhoek 61: $175-183$.

15. Romersburg, H. C. 1984. Cluster analysis for research. Lifetime Learning Publications, Belmont, Calif.

16. Sneath, P. H. A. 1978. Classification of microorganisms, p. 9/1-9/13. In J. R. Norris and M. H. Richmond (ed.), Essays in microbiology. Wiley, London.

17. Ståhl, M., G. Molin, A. Persson, S. Ahrné, and S. Ståhl. 1990. Restriction endonuclease patterns and multi-variate analysis as a classification tool for Lactobacillus spp. Int. J. Syst. Bacteriol. 40:189-193.

18. Vescovo, M., F. Dellaglio, V. Bottazzi, and P. G. Sarra. 1979. Deoxyribonucleic acid homology among Lactobacillus species of the subgenus Betabacterium Orla-Jensen. Microbiologica 2:317-330. 